anales de psicología, 2018, vol. 34, nº 2 (may), 241-250 http://dx.doi.org/10.6018/analesps.34.2.295331
CC Copyright 2018: Editum. Servicio de Publicaciones de la Universidad de Murcia. Murcia (Spain) ISSN print edition: 0212-9728. ISSN web edition (http://revistas.um.es/analesps): 1695-2294

\title{
Pathways from Positive and Negative Affect to Depressive Symptoms: Multiple Mediation of Emotion Regulation Strategies
}

\author{
Mehmet Ali Yıldız*, and Seval Kızıldağ
}

Adyaman University (Turkey).

\begin{abstract}
Título: Vías del afecto positivo y negativo a los síntomas depresivos: mediación múltiple de las estrategias de regulación de la emoción.

Resumen: El presente estudio tiene como objetivo examinar las múltiples mediaciones de las estrategias de regulación de las emociones en la relación entre el afecto positivo y negativo y los síntomas depresivos en los adolescentes. Los participantes fueron 290 estudiantes que asisten a escuelas intermedias en una ciudad de tamaño medio en la región del sudeste de Anatolia. Entre los estudiantes, 137 eran mujeres (47.2\%) y $153(52.8 \%)$ eran hombres. Las edades de los participantes variaron entre 9 y 15 con una media de $12.12, D T=1.53$. Los datos de la investigación se recogieron a través del Programa de Afecto Positivo y Negativo para Adolescentes, la Escala de Regulación de la Emoción para Adolescentes y la Escala de Depresión para Niños. El análisis de los datos se realizó mediante estadística descriptiva, coeficiente de correlación de Pearson, un enfoque basado en la regresión de mínimos cuadrados ordinarios y el método de Bootstrap. Los resultados de la investigación indicaron que la mediación de la regulación de la emoción disfuncional externa, la regulación interna de la emoción disfuncional y la regulación externa de la emoción funcional en las relaciones entre las emociones positivas y los síntomas depresivos fue estadísticamente significativa. Sin embargo, la mediación de la regulación de la emoción funcional interna no fue estadísticamente significativa. En la relación entre las emociones negativas y los síntomas depresivos, se encontró que la mediación de la regulación de la emoción interna disfuncional y la regulación de la emoción funcional externa es estadísticamente significativa. Además, la mediación de la regulación de la emoción funcional interna y la regulación de la emoción disfuncional externa no se encontró estadísticamente significativa. Los hallazgos de la investigación se discutieron en base a la literatura relevante y se presentaron algunas sugerencias para los investigadores.

Palabras clave: afecto positivo, afecto negativo, estrategias de regulación de las emociones, síntomas depresivos, adolescentes.
\end{abstract}

\section{Introduction}

Adolescence is a developmental period that is associated with some challenging physical and psychological changes along with stress. Some studies revealed that adolescents have some emotional transition, marked by changes in the way individuals view themselves and in their capacity to function independently (Hashmi, 2013). In adolescence, individuals is in a crucial phase in life and the presence of conditions like depression, anxiety and stress at this stage of life is a matter of concern (Bhasin, Sharma, \& Sain, 2010). Depressive symptoms in adolescents may be observed as relatively chronic unhappiness, anxiety and sense of void, pessimism and hopelessness, guiltiness and helplessness, loss of energy, exhaustion, difficulty sleeping, pain experienced due to no particular factors, pain or eating disorders (National Mental Health Institute, 2016). Depression among these moods is considered the most widely spread mental disorder

* Correspondence address [Dirección para correspondencia]:

Mehmet Ali Yıldız, Adiyaman University, Faculty of Education, Department of Guidance and Psychological Counseling, 02040 Adiyaman (Turkey).E-mail: maliyildiz@adiyaman.edu.tr ; alipdr@hotmail.com
Abstract: The current study aims to examine the multiple mediations of emotion regulation strategies in the relationship between positive and negative affect and depressive symptoms in adolescents. Participants included 290 students attending middle schools in a mid-size city in Southeastern Anatolian region. Among students, 137 were females (47.2\%) and 153 $(52.8 \%)$ were males. Participants' ages ranged between 9 and 15 with a mean of $12.12, S D=1.53$. Research data were collected through Positive and Negative Affect Schedule for Adolescents, Emotion Regulation Scale for Adolescents, and Depression Scale for Children. Data analysis was conducted through descriptive statistics, Pearson correlation coefficient, an approach based on Ordinary Least Squares Regression, and Bootstrap method. Research findings indicated that the mediation of external dysfunctional emotion regulation, internal dysfunctional emotion regulation, and external functional emotion regulation in the relationships between positive emotions and depressive symptoms was statistically significant. However, the mediation of internal functional emotion regulation was not found to be statistically significant. In the relationship between negative emotions and depressive symptoms, the mediation of internal dysfunctional emotion regulation and external functional emotion regulation was found to be statistically significant. In addition, the mediation of internal functional emotion regulation and external dysfunctional emotion regulation was not found statistically significant. Research findings were discussed based on the relevant literature and some suggestions for researchers were put forward.

Keywords: positive affect, negative affect, emotion regulation strategies, depressive symptoms, adolescents. that affects around 350 million people (approximately 5\% of the global population) globally (WHO, 2014). World Health Organization (2014) described depression as a common mental disorder, portrayed with continuing sadness, loss of interest and pleasure, feelings of guilt and worthlessness, disturbed sleep and appetite, exhaustion, and weak concentration, that could hurt an individual's functionality at home, work or school. Also, according to DSM-V, depression can be experienced in a lower mood than normal and individuals describe this as feeling unhappy, grieving, being discouraged, feeling sad, and many states to define sadness (Morrison, 2016). According to research data of National Mental Health Institute (2016), compared to previous year, approximately 3 million adolescents between ages 12 and 17 have at least one depression symptom and this rate consists of almost $12 \%$ of the USA population. Also, according to Turkey Statistical Institution (2013) data, $69.6 \%$ of adolescents stated that they were happy in 2011 and this was down to $64.6 \%$ in 2012. In $2011,5.4 \%$ of youth stated that they were unhappy and in 2012, this was $9.4 \%$. According to the report published by WHO in 2015, approximately 3 million 260 thousand individuals in Turkey suffer from depression and this is $4.4 \%$ of 
the country population (WHO, 2015). These statistical data indicate that depression is a common mental disorder both around the world and in Turkey and it becomes more complicated with emotional changes experienced in adolescence. Considering the risk that depression poses towards adolescents' well-being, regulating the emotions emerging in depression may be critical for the continuation of adolescents' mental health. On the other hand, it may be said that adolescents' ability to regulate emotions can have a defining role in both their present development process and their future health as adults.

According to Gross (1998), emotion regulation involves individuals' emotions, when they had these emotions, and the processes of how they experience them and how they express those. According to Koole (2009), emotion regulation involves all emotional regulations including moods, stress and positive or negative affect. When individuals emotionally react to incidents in daily life, they react to regulate their emotions to adapt to the situation. Some of those emotions may be functional and adaptive as well as dysfunctional and painful towards individual's adjustment (Y1ldiz, 2014). For example, McLaughlin, Hatzenbuehler, Mennin, \& Nolen-Hoeksama (2012) stated that adolescents experiencing challenges in emotion regulation tended to develop psychopathology. During emotion regulation, individuals may continue, reduce or increase their negative or positive emotions; thus, emotion regulation often includes the changes in emotional reactions (Gross, 1999). In other words, the purpose of regulating individuals' emotions is to increase positive affect and reduce negative affect. In general, positive affects refer to an individual's state of being happy, strong, energetic, joyful, glad, pleased, and lively. Negative affects involve being sad, nervous, tense, miserable, scared, lonely, and fed up (Ylldız, 2014). Positive and negative affect that individuals experience are critical in predicting mental disorders (Leue \& Langei, 2011). It is known that individuals mostly experience negative affects during depression (Baytemir \& Y1ldız, 2017) For instance, some clinical studies showed that ineffective and dysfunctional emotion regulation was a significant dimension when disorders such as depression and anxiety emerge and progress (Barlow, Allen, \& Choate, 2004; Duy \& Yld1z, 2017; Mennin, 2006). Based on this, it can be said that an individual's effective emotion regulation against intense negative affects may return the course of depression from negative to positive.

Gross, Richards, and John (2006) categorized as emotion regulation strategies in two basic categories: they conceptualized the emotion regulation strategy reflecting health and function as cognitive reappraisal and unhealthy and dysfunctional strategy as suppression. John and Gross (2004) found a positive relationship between reappraisal strategy and positive emotions and the expression of positive emotions and a low-level relationship between negative emotions and reappraisal. On the other hand, Gross (2008) recently stated that emotion regulation strategies could be categorized as internal and external. In relevant literature, internal dysfunctional emotion regulation was described as self-damaging, rumination, suppression, negative social comparison, and de-realization; internal functional emotion regulation strategy as reappraisal, change of goals, planning, setting into perspective, and paying attention; external dysfunctional emotion regulation as bullying, verbal attacking, physical attacking, hitting or breaking things, and trying to make others feel bad; external functional emotion regulation as expressing feelings, seeking advice, physical contact, and exercising (Duy \& Yildız, 2014; Phillips \& Power, 2007; Yildı, 2016). It is seen that, in emotion regulation, internal functional and external functional emotion regulation strategies refer to being psychologically healthy.

A review of recent discussion in relevant literature indicated that depressive individuals used inappropriate or ineffective emotion regulation strategies; they had difficulties using cognitive control; they had difficulties processing negative material/situation (where greater regression was experienced, reappraisal was reduced, and suppression was increased); and they had negative judgments of self-expression (Compare, Zarbo, Shonin, Gordon, \& Marconi, 2014). For instance, Siener and Kerns (2012) examined the relationships between emotion regulation and depressive symptoms in children aged 10-12 and found that children with depressive symptoms had difficulties regulating emotions. Also, depressive patients were found to use internal dysfunctional emotion regulation strategies such as rumination and suppression very often and, however, internal functional emotion regulation strategies such as reappraisal very rarely (Arditte \& Joormann, 2011; Campbell-Sills, Barlow, Brown \& Hofmann, 2006; Gross \& John, 2003; Smith \& Alloy, 2009). Nevertheless, studies indicate that rumination was a significant predictor of depression (Nolen-Hoeksema, 2000; Nolen-Hoeksema, Stice, Wade, \& Bohon, 2007; Singer \& Dobson, 2007). Garnefski, Kraaij, and Etten (2005) examined the relationships of adolescents' cognitive emotion regulation strategies between internalized an externalized psycho-pathologies. Self-blame and rumination strategies were encountered more with internal dysfunctional internalized psycho-pathologies (such as introversion, anxiety, and depression) and positive refocus was found more along with externalized pathologies (such as behavioral disorders, aggression, hyperactivity). Self-blame or self-blaming attributions were associated with high-level depression (Anderson, Miller, Riger, Dill, \& Sedikides, 1994; Kubany, Haynes, Abueg, Manke, Brennan, \& Stahura, 1996). Self-blame, rumination, catastrophizing, and positive reappraisal were found to be the most effective strategies in case of negative emotions in a research examining the definitive role of cognitive emotion regulation in emerging depression, anxiety, stress, and anger (Martin \& Dahlen, 2005). Joorman and Gotlib (2010) compared individuals diagnosed and not diagnosed with depression. The researchers found that those diagnosed with depression used cognitive reappraisal approach less than other groups did; however, groups did not differ in expressional suppression and stated that not using cognitive reappraisal against negative emotions may lead to both 
emerging and continuing depressive symptoms. Hence, it may be said that emotion regulation strategies are effective not only in depression but also depressive symptoms. Duy and Yildiz (2017) found that adolescents using dysfunctional emotion regulation strategies had high levels of both depressive and psycho-somatic symptoms. In another study with clinical and non-clinical individuals, Garnefski, Kommer, Kraaij, Teerds, Legers-Tee, and Onstein (2002) found that self-blame and catastrophizing were used more in clinical sample and positive reappraisal was used more in nonclinical sample. Yildiz (2016) found that the mediation of internal functional emotion regulation, dysfunctional emotion regulation, and external functional emotion regulation were statistically significant and the mediation of external dysfunctional emotion regulation was not statistically significant in a research on the mediating role of emotion regulation strategies in the relationship between loneliness and positivity in adolescents. In another research, Verzeletti, Zammuner, Galli, and Agnoli (2016) found relationships between cognitive reappraisal as a functional emotion regulation strategy in adolescents and positive affects, life satisfaction, and psychological health. In addition, negative relationships were found between suppression as a dysfunctional emotion regulation strategy and psychological health, life satisfaction, and positive affects as well as positive relationships between suppression and emotional loneliness and negative affects. Thus, a review of relevant literature showed close relationships between positive and negative affect and emotion regulation strategies and depressive symptoms. From this point of view, it is possible to say that the difficulty experienced by adolescents in regulating their emotions influences self-accusation, aggression, hyperactivity, psychosomatic symptoms, life satisfaction and general mental health, either directly or indirectly. Given the negativity of this effect, the emotion that may pose a risk for the psychological well-being and integrity of the adolescent is likely to be the possibility that the difficulty experienced may lead to greater problems.

\section{Rationale and Hypotheses}

In short, positive and negative affect in adolescents can be said to predict depressive symptoms in adolescents through the mediation of internal functional and internal dysfunctional and external functional and external dysfunctional emotion regulation strategies. It is an important requirement to understand adolescents' depressive symptoms and conduct relevant intervention for adolescents to have continuous mental health and well-being. Based on the results of the current research, mental health professionals such as psychiatrists, psychologists, and counselors working with adolescents may take on a facilitative role in understanding the effects of emotion regulation processes on the symptoms and in developing interventions against adolescents' depressive symptoms. In addition, adolescents' experience of positive emotions through use of healthy and functional emotion regulation strategies in adolescence may be positively con- tributive in living as whole and healthy adults. Hence, the current study aims to examine the multiple mediations of emotion regulation strategies in relationships between positive and negative affect and depressive symptoms in adolescents.

\section{Method}

Relational design as a research approach was used in the current study. According to Heppner, Wampold, and Kivlighan (2013), relational designs are used to examine relationships among two or more variables. In the current study, relationships between variables were examined through mediation analyses. Predictive variables in the current research consisted of positive and negative affect; mediating variables were emotion regulation strategies; and the outcome variable was the depressive symptoms.

\section{Participants}

Participants included a total of 290 students attending schools during 2015-2016 academic years in a mid-size city in southeastern Anatolian region in Turkey. 137 (47.2\%) students were females and $153(52.8 \%)$ were males. Ages of the participants ranged between 9 and 15 with a mean of 12.12 , $S D=1.53$. Participants were selected through convenience sampling. In convenience sampling, the researchers select the participants based on factors such as cost, time, and ease of access to the study sample (Cohen, Manion, \& Morrison, 2007)

\section{Measures}

Positive and Negative Affect Schedule for Adolescents (PANASA): Positive and Negative Affect Schedule for Adolescents was developed by Laurent et al. (1999). The adaptation study into Turkish language of PANAS-A was conducted by Yildiz (2014). PANAS-A consist of 14 items with 7 positive and 7 negative items. The cross-validity (measurement equivalence) of the scale on gender was provided in Yildiz's (2014) study. Upon confirmatory factor analysis (CFA) on data from two separate study groups, the scale was found to have a good fit. In addition, alpha values obtained on two separate groups were found as .89 and .91 for positive affect and .79 for negative affect; the composite reliability (CR) values were found as .89 and .91 for positive affect and .79 for negative affect; average variance extracted (AVE) values were found as .71 and .76 for positive affect and .46 for negative affect. For the test-retest reliability, 63 students took PANAS-A with an interval of three weeks and through correlation analyses, significant relationships were found on levels of $r=.70, p<$ .01 , for positive affect dimension and $r=.63, p<.01$, for negative affect dimension. In the scale validity study, both dimensions of PANAS-A were found to have significant relationships with life satisfaction and depressive symptoms.

The Regulation of Emotions Questionnaire (REQ) for Adoles- 
cents: The adaptation study into Turkish language for the scale, developed by Phillips and Power (2007), was conducted by Duy and Yildiz (2014). The scale consists of 17 items with 5-point Likert-type scoring ( $1=\mathrm{Never}$ 5=Always). REQ factor loadings were found to be between .53 and .77 in the exploratory factor analysis conducted for the construct validity of the scale. Four dimensions of the scale overall explained $51.48 \%$ of the total variance. The fit indices obtained on the confirmatory factor analysis, on the other hand, were as follows: $\mathrm{RMSEA}=.06, \mathrm{RMR}=.09, \mathrm{SRMR}=.06, \mathrm{GFI}=$ $.94, \mathrm{AGFI}=.92, \mathrm{CFI}=.93, \mathrm{NFI}=.91$, and NNFI $=.92 . \mathrm{In}$ REQ theoretical substructure, emotion regulation strategies such as self-mutilation, rumination, suppression, negative social comparison, and de-realization on the internal dysfunctional emotion regulation dimension (for instance: "I keep the feeling locked up inside"); positive reappraisal, replacing goals, planning, fitting in the perspective, and focusing within internal functional emotion regulation (for instance: "I review (re-think) my thoughts or beliefs"); bullying, verbal attacking, physical attacking, hitting or breaking things, and trying to make others feel bad within external dysfunctional emotion regulation (for instance: "I bully other people (e.g. saying nasty things to them, hitting them)"); expressing emotions, seeking advice, establishing physical relationship, and exercising within external functional emotion regulation (for instance: "I ask others for advice") were determined (Yıldız, 2016). The scale aiming to measure adolescent strategies of emotion regulation has four sub-scales, named as internalfunctional emotion regulation $(\alpha=.75)$, external-functional emotion regulation $(\alpha=.57)$, internal-dysfunctional emotion regulation $(\alpha=.71)$, and external-dysfunctional emotion regulation $(\alpha=.74)$. Total score obtained from a sub-scale indicates how often the relevant emotion regulation strategy is being used. Higher scores mean more frequent use of a strategy. Test-retest reliability analysis yielded satisfactory results (Duy \& Yıldız, 2014; Yildız, 2016).

Children's Depression Inventory (CDI): Validity and reliability studies in Turkey for the scale originally developed by Kovacs (1981) were conducted by Öy (1991). The test-retest value for the scale was found as $r=.80$. To test the validity of the scale, 59 students, randomly selected from each class, were interviewed for depression and Childhood Depression Grading Scale was applied. Depression diagnosis was based on DSM-III criteria. Hence, considering students with major depression and depressive symptoms, the sensitivity of the scale was found as $60 \%(n=60)$. For those children, Pearson moment product correlation of total scores on Children's Depression Inventory and Childhood Depression Grading Scale was found as $r=.61$ (Öy, 1991).

\section{Procedure}

The data for the current research were collected during instruction upon obtaining permission from the Department of Education. Volunteering students were included in the study. The purpose and scale guidelines of study by the researchers are explained to the students. Measures were administered in nearly 15 minutes. Data analysis was conducted through descriptive statistics, Pearson correlation coefficient, an approach based on Ordinary Least Squares Regression, and Bootstrap method. The statistical significance of the model tested in the current research was examined through software developed by Hayes (2013, 2016), an approach based on ordinary least squares regression, and Bootstrap method. Bootstrap analyses in the current research involved Multiple Mediation Model 4 run through PROCESS Macro with parallel multiple mediation. The statistical significance of the mediation of mediating variables was examined on 5000 Bootstrap samples. Upon consideration of relevant literature including gender as a defining effect in relation to depressive symptoms, Gender was set to be the controlling variable (covariate) to test this effect. The significance level was set as .05 in the current study. IBM SPSS 22.0 was used in the research data analysis.

\section{Findings}

Descriptive statistics and correlation values associated with the research variables are presented in Table 1.

Table 1. Descriptive Statistics and Pearson Correlation Coefficient Values Regarding Study Variables.

\begin{tabular}{|c|c|c|c|c|c|c|c|}
\hline Variables & 1 & 2 & 3 & 4 & 5 & 6 & 7 \\
\hline 1. Positive Affect & $\overline{---}$ & & & & & & \\
\hline 2. Negative Affect & $-.40 * *$ & --- & & & & & \\
\hline 3. Inter.Func.Emot.Reg. & $.21 * *$ & $-.19 * *$ & --- & & & & \\
\hline 4. Extr.Func.Emot.Reg. & $.35^{* *}$ & $-.16^{* *}$ & $.37 * *$ & --- & & & \\
\hline 5. Inter.Dysfun.Emot.Reg. & $-.21 * *$ & $.47 * *$ & $-.15^{*}$ & -.04 & --- & & \\
\hline 6. Ext.Dysfun.Emo.Reg. & $-.17 * *$ & $.44 * *$ & $-.29 * *$ & -.06 & $.47 * *$ & --- & \\
\hline 7. Depressive symptoms & $-.50 * *$ & $.61 * *$ & $-.17 * *$ & -.24 & $.52 * *$ & $.40 * *$ & --- \\
\hline Mean & 27.08 & 15.11 & 15.48 & 13.14 & 12.37 & 9.53 & 12.42 \\
\hline $\mathrm{SD}$ & 6.22 & 95.3 & 3.43 & 3.83 & 4.23 & 4.33 & 7.06 \\
\hline Skewness & -.73 & .77 & -.83 & -.12 & .34 & 1.01 & .87 \\
\hline Kurtosis & -.22 & .42 & .56 & -.57 & -.41 & .48 & .70 \\
\hline
\end{tabular}


A review of Table 1 shows negative significant-level relationships between positive and negative affect, external dysfunctional emotion regulation, internal dysfunctional emotion regulation, and depressive symptoms. On the other hand, positive significant-level relationships were found between positive affect and internal functional emotion regulation and external functional emotion regulation. Negative significant relationships were found between negative affect, internal functional emotion regulation, and external functional emotion regulation. Positive significant relationships were found between negative affect, external dysfunctional emotion regulation, internal dysfunctional emotion regulation, and depressive symptoms. Kurtosis and skewness values between the accepted +1 and -1 (Tabachnick and Fidell, 2013) indicate that the data in the current study are normally distributed.

Test results, associated with the parallel multiple mediation of emotion regulation strategies between positive affect and depressive symptoms, are presented in Figure 1.

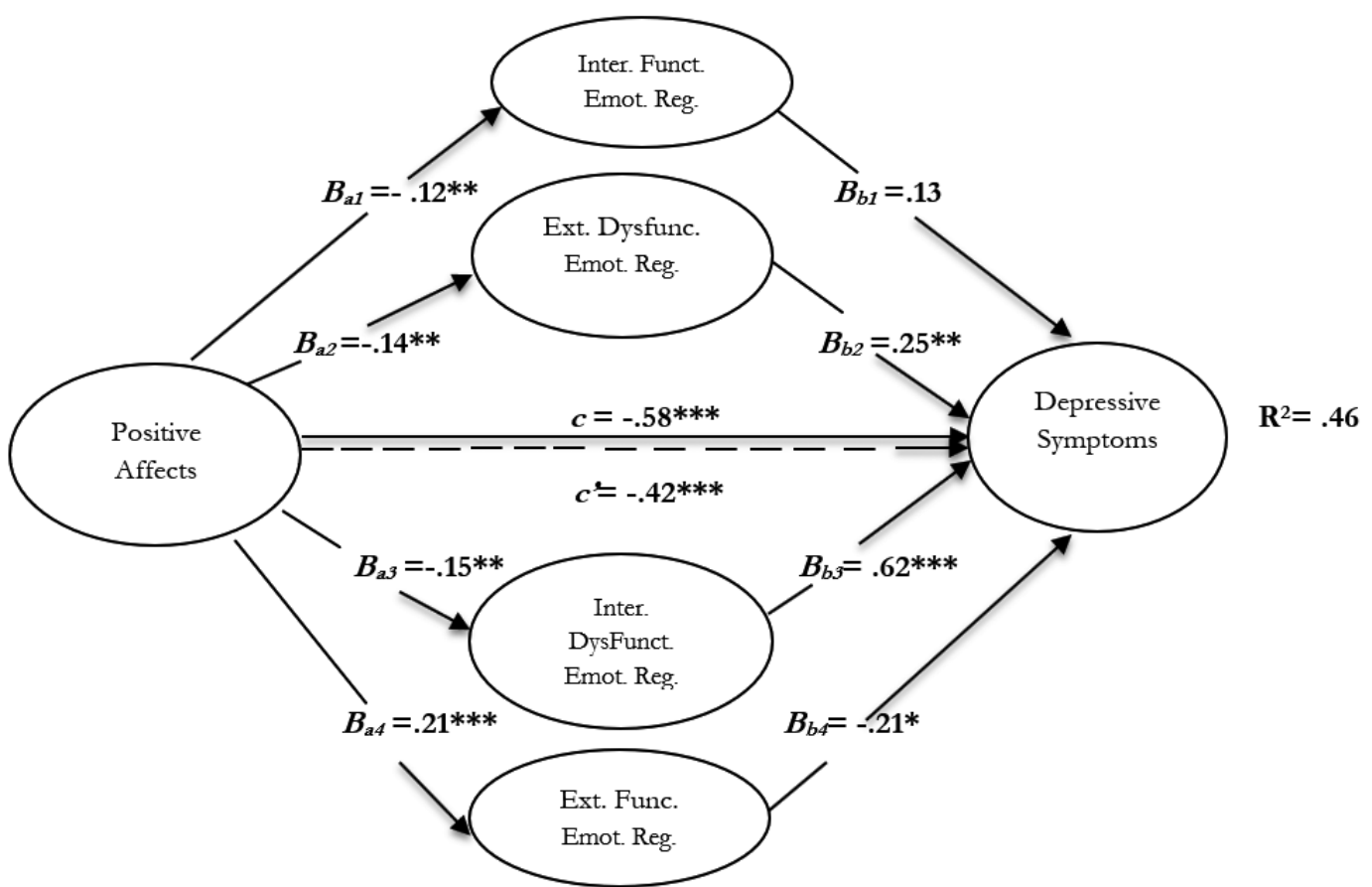

Figure 1. Parallel-Multiple Mediation of Emotion Regulation Strategies between Positive Affects and Depressive Symptoms and Non-Standardized Beta Values. ${ }^{*} p<.05,{ }^{* *} p<.01,{ }^{* * *} p<.001$.

Figure 1 indicates that total effect of positive emotions on depressive symptoms $(c=-.58, \mathrm{SE}=.06, t=-10.06, p<$ $.001)$ was on significant level (Step1). Direct effects of positive affect as predicting variable on mediating variables of internal functional emotion regulation $(\mathrm{B}=.12, \mathrm{SE}=.03, t=$ 3.96, $p<.01)$, external dysfunctional emotion regulation (B $=-.14, \mathrm{SE}=.04, t=-3.81, p<.01)$, internal dysfunctional emotion regulation $(\mathrm{B}=-.15, \mathrm{SE}=.04, t=-3.79, p<.01)$ and external functional emotion regulation $(\mathrm{B}=.21, \mathrm{SE}=.03, t$ $=6.18, p<.001$ ) were on significant levels (Step 2). Direct effects of mediating variables, external dysfunctional emotion regulation $(\mathrm{B}=.25, \mathrm{SE}=.09, t=2.82, p<.01)$, internal dysfunctional emotion regulation $(\mathrm{B}=.62, \mathrm{SE}=.08, t=$ $7.47, p<.001)$ and external functional emotion regulation $(\mathrm{B}$ $=-.21, \mathrm{SE}=.09, t=-2.36, p<.05)$, on depressive symptoms were found on significant levels. Also, the effect of internal functional emotion regulation $(\mathrm{B}=.13, \mathrm{SE}=.10, t=1.27, p$ $>$.05) on depressive symptoms was not found on significant levels (Step 3). When positive affect and mediating variables were simultaneously entered in the equation (Step 4), the relationship between positive affect and depressive symptoms was reduced and significance value was found to be on the same level $\left(c^{\prime}=-.42, \mathrm{SE}=.05, \mathrm{t}=-7.73, p<.001\right)$. Based on this result, three mediating variables were seen to mediate between positive affect and depressive symptoms. Also, the model as a whole was on significant levels $\left(F_{(6-283)}=40.80, p\right.$ $<.001)$ and the model explained $46 \%$ of the total variance.

The comparison of indirect effects of adolescents' positive affect through emotion regulation strategies on depressive symptoms and their specific indirect effects are presented in Table 2. 
Table 2. Comparison of the Indirect Effects of Positive Affects of Adolescents on Depressive Symptoms through Emotion Regulation Strategies.

\begin{tabular}{|c|c|c|c|c|c|c|}
\hline \multirow[b]{2}{*}{ Effects } & \multirow[b]{2}{*}{ Point Estimate } & \multicolumn{3}{|c|}{ Product of Coefficients } & \multicolumn{2}{|c|}{$\begin{array}{l}\text { Bootstrapping } 95 \% \mathrm{BCa} \\
\text { Confidence Interval }\end{array}$} \\
\hline & & SE & $z$ & $p$ & Lower & Upper \\
\hline Total Indirect Effects & -.1587 & .0441 & & & -.2471 & -.0768 \\
\hline Inter. Funct. Emot. Reg. & 0161 & .0165 & 1.1775 & .2390 & -.0128 & .0536 \\
\hline Exter. Funct. Emot. Reg. & -.0454 & .0221 & -2.1818 & 0291 & -.0943 & -.0078 \\
\hline Inter. Dysfunct. Emot. Reg. & -.0933 & .0322 & -3.3583 & .0008 & -.1634 & -.0378 \\
\hline Exter. Dysfunct. Emot. Reg. & -.0360 & .0185 & -2.2175 & .0266. & -.0852 & -.0081 \\
\hline \multicolumn{7}{|l|}{ Contrasts } \\
\hline C1 & .0521 & .0271 & & & .0067 & .1144 \\
\hline $\mathrm{C} 2$ & .1094 & .0355 & & & .0469 & .1853 \\
\hline C3 & .0615 & .0325 & & & .0042 & .1325 \\
\hline
\end{tabular}

The statistical significance of the indirect effects on the model tested in the current research was examined through 5000 Bootstrap samples. Estimations were tested within the 95\% confidence interval and bias corrected and accelerated results are included in Table 2. Table 2 indicates that indirect total effect of positive affect, through the strategies of emotion regulation, on depressive symptoms (namely, the difference between the total and direct effect $/ \mathrm{c}-c)$ is statistically significant (point estimation= -.1587 and 95\% BCa CI [$.2471,-.0768])$. When the four mediating variables were separately considered in relation to mediation for indirect effects of positive affect on depressive symptoms within the tested model, the mediations of external functional emotion regulation (point estimation= -.0454 and 95\% BCa CI[-.0943, .0078 internal dysfunctional emotion regulation (point estimation= -.0933 and 95\% BCa CI[-.1634, -.0378]), and external dysfunctional emotion regulation (point estimation $=$ .0360 and $95 \%$ BCa CI[-.0852, -.0081]),]) were found statis- tically significant. On the other hand, the mediation of internal-functional emotion regulation (point estimate $=.0161$ and $95 \%$ BCa CI $[-.0128, .0536])$ was not found statistically significant. Paired comparisons were conducted in order to define the powers of mediating variables. Statistically significant three comparisons with point estimates outside the zero interval, based on $95 \%$ confidence interval, were included in Table 2. Based on the paired comparisons of certain indirect effects, external dysfunctional emotion regulation (C1), internal dysfunctional emotion regulation (C2), and external functional emotion regulation (C3) were found to be more powerful mediators than internal functional emotion regulation was. However, other paired comparisons were not found as statistically significant.

Test result associated with the parallel multiple mediations of emotion regulation strategies in the relationship between negative affect and depressive symptoms is presented in Figure 2.

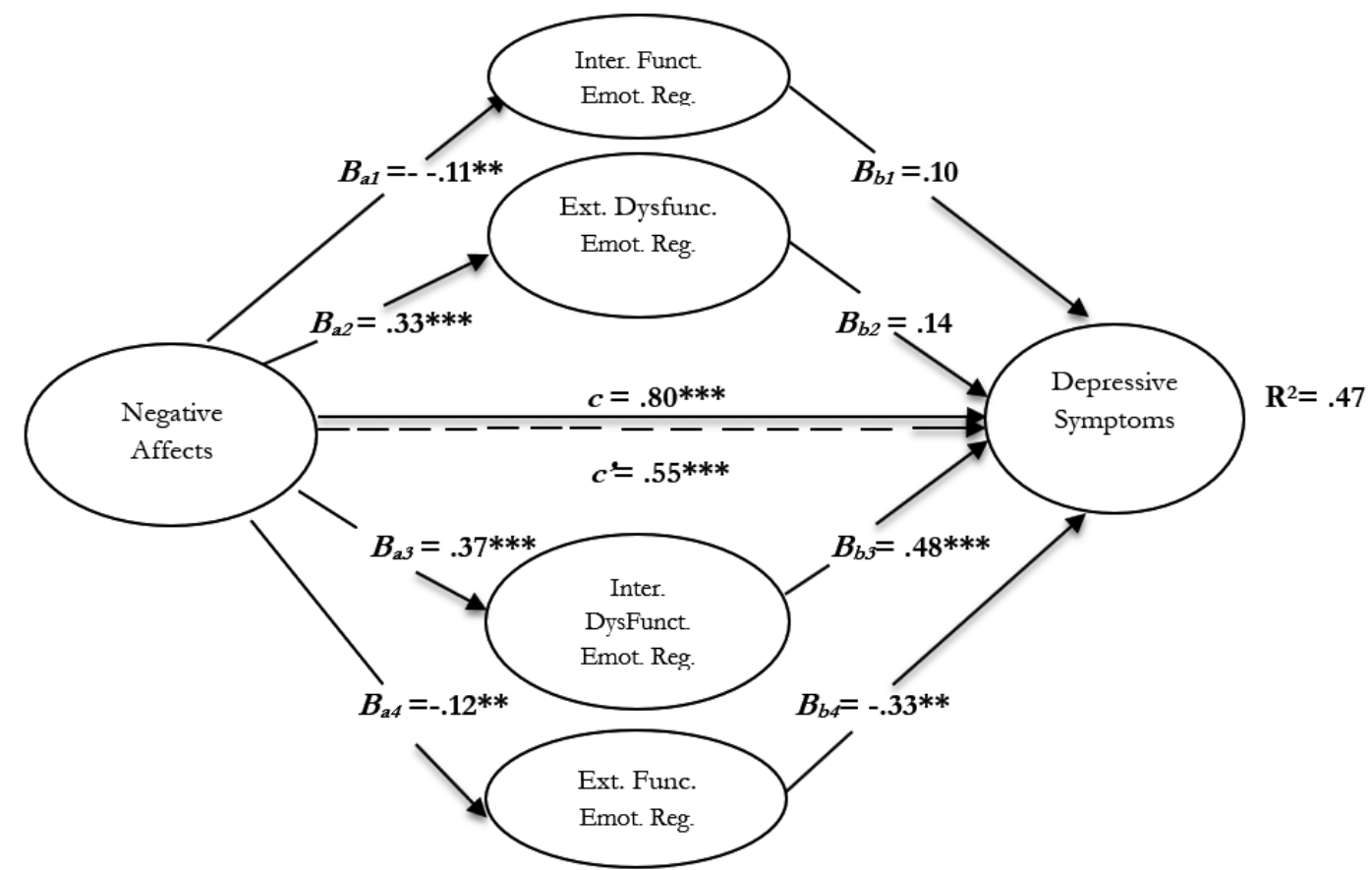

Figure 2. Parallel-Multiple Mediation of Emotion Regulation Strategies between Negative Affects and Depressive Symptoms and Non-Standardized Beta Values. ${ }^{*} p<.05,{ }^{* *} \mathrm{p}<.01,{ }^{* * *} p<.001$. 
Figure 2 indicates that the total effect of negative affect on depressive symptoms $(\mathrm{c}=.80, \mathrm{SE}=.06, t=12.88, p<$ .001) was on significant levels (Step 1). The direct effects of negative affect as predicting variable on mediating variables of internal functional emotion regulation $(\mathrm{B}=-.11, \mathrm{SE}=.04$, $t=-3.07, p<.01)$, external dysfunctional emotion regulation $(\mathrm{B}=.33, \mathrm{SE}=.04, t=7.96, p<.001)$, internal dysfunctional emotion regulation $(\mathrm{B}=.37, \mathrm{SE}=.04, \mathrm{t}=8.93, p<.001)$, and external functional emotion regulation $(\mathrm{B}=-.12, \mathrm{SE}=.04, t$ $=-2.81, p<.01$ ) were on significant levels (Step 2). Direct effects of mediating variables, internal dysfunctional emotion regulation $(\mathrm{B}=.48, \mathrm{SE}=.09, t=5.50, p<.001)$ and external functional emotion regulation $(\mathrm{B}=-.33, \mathrm{SE}=.09, t=-3.79$, $p<.01)$, on depressive symptoms were found on significant levels. However, the effects of internal functional emotion regulation $(\mathrm{B}=.10, \mathrm{SE}=.10, t=.96, p>.05)$ and external dysfunctional emotion regulation $(\mathrm{B}=.14, \mathrm{SE}=.09, t=$ $1.58, p>.05)$ on depressive symptoms were not found on significant levels (Step 3). When negative affect and mediating variables were simultaneously entered in the equation (Step 4), the relationship between negative affect and depressive symptoms was reduced and significance value was found to be on the same level ( $c^{\prime}=.55, \mathrm{SE}=.07, \mathrm{t}=8.11, p<$ $.001)$. Based on this result, two mediating variables were seen to mediate between negative affect and depressive symptoms. Also, the model as a whole was on significant levels $\left(F_{(6-283)}=42.33, p<.001\right)$ and the model explained $47 \%$ of the total variance.

The comparison of indirect effects of adolescents' negative affect through emotion regulation strategies on depressive symptoms and their specific indirect effects are presented in Table 3.

Table 3. Comparison of the Indirect Effects of Negative Affects of Adolescents on Depressive Symptoms through Emotion Regulation Strategies

\begin{tabular}{|c|c|c|c|c|c|c|}
\hline \multirow[b]{2}{*}{ Effects } & \multirow[b]{2}{*}{ Point Estimate } & \multicolumn{3}{|c|}{ Product of Coefficients } & \multicolumn{2}{|c|}{$\begin{array}{c}\text { Bootstrapping } 95 \% \mathrm{BCa} \\
\text { Confidence Interval }\end{array}$} \\
\hline & & SE & $\mathrm{z}$ & $p$ & Lower & Upper \\
\hline Total Indirect Effects & .2500 & .0517 & & & .1600 & .3626 \\
\hline Inter. Funct. Emot. Reg. & -.0109 & .0138 & -.8762 & .3089 & -.0446 & .0117 \\
\hline Exter. Funct. Emot. Reg. & .0384 & .0173 & 2.2084 & .0272 & .0117 & .0814 \\
\hline Inter. Dysfunct. Emot. Reg. & .1763 & .0476 & 4.6606 & .0000 & .0960 & .2831 \\
\hline Exter. Dysfunct. Emot. Reg. & .0461 & .0310 & 1.5398 & .1236 & -.0093 & .1108 \\
\hline
\end{tabular}

\begin{tabular}{llll} 
Contrasts & & & \\
\hline C2 & -.1872 & .0486 & -.2987 \\
C3 & -.0493 & .0260 & -.1044 \\
C4 & -.1303 & .0618 & -.0086 \\
C6 & .1379 & .0516 & -.2643 \\
\hline
\end{tabular}

$\mathrm{n}=290, k=5000,{ }^{*} p<.05,{ }^{* *} p<.01,{ }^{* * *} p<.001$, Control Variables = Gender, BCa: Bias Corrected and Accelerated 5000 bootstrap samples

The statistical significance of the indirect effects on the model tested in the current research was examined through 5000 Bootstrap samples. Estimations were tested within the $95 \%$ confidence interval and bias corrected and accelerated results are included in Table 3. Table 3 indicates that indirect total effect of negative affect, through the strategies of emotion regulation, on depressive symptoms (namely, the difference between the total and direct effect $/ \mathrm{c}-c$ ) is statistically significant (point estimation $=.25$ and $95 \%$ BCa CI [.16, .3626]). When the four mediating variables were separately considered in relation to mediation for indirect effects of negative affect on depressive symptoms within the tested model, the mediations of external functional emotion regulation (point estimate $=.0384$ and 95\% BCa CI [.0117, .0814]) and internal dysfunctional emotion regulation (point estimate $=.1763$ and 95\% BCa CI $[.0960, .2831]$ ) were found statistically significant. On the other hand, the mediations of internal functional emotion regulation (point estimate= .0109 and $95 \%$ BCa CI [-.0446, .0117]) and external dysfunctional emotion regulation (point estimate $=.0461$ and $95 \%$ BCa CI $[-.0093, .1108])$ was not found statistically significant. Paired comparisons were conducted in order to define the powers of mediating variables. Statistically significant four comparisons with point estimates outside the zero interval, based on $95 \%$ confidence interval, were included in Table 3. Based on the paired comparisons of specific indirect effects, internal dysfunctional emotion regulation (C2) and external functional emotion regulation (C3) were found to be more powerful mediators than internal functional emotion regulation was. On the other hand, internal dysfunctional emotion regulation was found to be a more powerful mediator than external functional emotion regulation (C6) and external dysfunctional emotion regulation (C4) were. In addition, other paired comparisons were not found as statistically significant.

\section{Discussion}

The research findings indicated that as positive emotions decreased, depressive symptoms increased through the mediation of external dysfunctional emotion regulation and internal dysfunctional emotion regulation strategies; however, as positive emotions increased, depressive symptoms decreased through the mediation of external functional emotion regulation strategies. It is understandable that when adolescents feel unhappy and less energetic, their use of external dysfunctional emotion regulation strategies such as bullying, 
verbal assault, physical assault, hitting and breaking things, and trying to make others feel bad lead to an increase in depressive symptoms. For instance, bullying leads to depression, low self-esteem, and problematic behaviors (Minton \& Minton, 2004; Pace, 2001). Particularly encountered in adolescence, this may be even more challenging for adolescents trying to cope with other intense emotions. Evans (1993) found, in a study with a group of inpatient adolescents and diagnosed with depression, anxiety, and conversion disorder, that the patients negatively perceived themselves in domains of school achievement, job competency, close friendship, and general self-worth. A reverse reading on this result may indicate that adolescents' perceptions of academic achievement, close friendship or self, possibly leading to unhappiness, can predict depressive symptoms. In addition, the finding about depressive symptoms increasing through mediation of internal dysfunctional emotion regulation strategies against decreasing positive emotions is understandable. Many studies in relevant literature seem to support this result (Arditte \& Joormann, 2011; Campbell-Sills et al., 2006; Gross, \& John, 2003; Duy \& Yildı, 2017; Garnefski, Kommer, Kraaij, Teerds, Legers-tee, \& Onstein, 2002; Nolen- Hoeksema, 2000; Nolen-Hoeksema, Stice, Wade, \& Bohon, 2007; Singer \& Dobson, 2007; Smith \& Alloy, 2009; Yıldız, 2016). In the mentioned studies, individuals with depressive symptoms were found to use internal dysfunctional emotion regulation strategies such as rumination and suppression. Also, internal dysfunctional emotion regulation strategies such as selfblame or self-blaming attribution and catastrophizing may be considered to have high-level relationships with depressive symptoms (Anderson, Miller, Riger, Dill, \& Sedikides, 1994; Kubany, Haynes, Abueg, Manke, Brennan, \& Stahura, 1996; Martin \& Dahlen, 2005). In addition, in the current research, the finding on the relationship between positive emotions and depressive symptoms indicated that as positive emotions increased, depressive symptoms decreased through the mediation of external functional emotion regulation strategies (expressing emotions, seeking advice, physical contact, and exercising). As such, adolescents are advantageous at better expressing themselves and in health communicating through their positive affect. Contrarily, indecision experienced in the expression of emotions may lead to negative emotions, obsessive-compulsive tendency, depression, paranoid thoughts, and anxiety (Collins \& Miller, 1994; Katz \& Campbell, 1994). An increase in positive emotions in individual may make him/her feel better; express negative feelings without suppressing them to regulate emotions due to problems and distress; relax upon receiving assistance and advice from others when required; and strengthen social relationships to decrease the experience of depressive symptoms.

Another finding in the current study indicated that the mediations of internal dysfunctional emotion regulation and external functional emotion regulation in the relationship between negative emotions and depressive symptoms were found statistically significant. However, the mediations of internal functional emotion regulation and external dysfunc- tional emotion regulation were not found statistically significant. In addition, paired comparisons conducted to define the mediating powers of mediating variables indicated that internal dysfunctional emotion regulation and external functional emotion regulation were more powerful mediators than internal functional emotion regulation was. On the other hand, internal functional emotion regulation was a stronger mediator than external dysfunctional emotion regulation and external functional emotion regulation were. Hence, findings in the current research indicated that as negative emotions increased, depressive symptoms increased through the mediation of internal dysfunctional emotion regulation and as negative emotions decreased, depressive symptoms decreased through the mediation of external functional emotion regulation. First of all, the finding about the increase in depressive symptoms due to negative emotions through the mediation of internal dysfunctional emotion regulation is compatible with direct or indirect research findings in the relevant literature (Anderson, Miller, Riger, Dill, \& Sedikides, 1994; Arditte \& Joormann, 2011; Brown \& Hofman, 2006; Campbell-Sills, Barlow, Gross, \& John, 2003; Duy \& Y1ldı, 2017; Garnefski, Kommer, Kraaij, Teerds, Legers-tee, \& Onstein, 2002; Kubany, Haynes, Abueg, Manke, Brennan, \& Stahura, 1996; Nolen-Hoeksema, 2000). Common result in those studies is about internal dysfunctional emotion regulation predicting depressive symptoms in a negative relationship with positive affect and in a positive relationship with negative affect. Secondly, another explainable finding in the current study was about depressive symptoms decreasing through the mediation of external functional emotion regulation against negative emotions decreasing. An adolescent that is able to experience more positive than negative emotions may be more open to communicate, to emotionally express themselves, and to socialize. With those characteristics and more, adolescent may be more recognized and supported by other individuals. Hence, the possibility of experiencing depressive symptoms in such a network of support is low. For instance, expressing feelings and thoughts may bring along psychological well-being (Kenndy-Moore \& Watson, 2001; Zech, 1998) as well as talking about problems may lead to a decrease in negative affect (Lepore, Ragan, \& Jones, 2000).

Upon examining the findings obtained and found to be statistically significant within the current study, other findings that were not statistically significant require some explanation. For instance, the mediation role of internal functional emotion regulation in the relationship between positive and negative affect and depressive symptoms in adolescents was not found to be statistically significant. This finding is in line with the results of some studies in the relevant literature Joorman \& Gotlib, 2010; Garnefski, Kommer, Kraaij, Teerds, Legers-tee, \& Onstein, 2002; Verzeletti, Zammuner, Galli, \& Agnoli, 2016; Yıldı, 2016). Internal functional emotion regulation, not mediating in the relationship between positive and negative affect and depressive symptoms, triggers the thought that other factors may have involved in this process. Hence, adolescents may be under the influence of 
family, culture, and personal factors when reappraising, regardless of being happy or unhappy. For instance, an adolescent considering some family and social factors, may exhibit depressive symptoms, without including his/her feelings about academic failure in the internal functional process of reappraisal. Particularly in Eastern societies with a collectivistic culture, individuals prioritize external rather than internal appraisal. However, in the current study, the mediating role of external dysfunctional emotion regulation in the relationship between negative affect and depressive symptoms was not found to be statistically significant. This finding is not compatible with the results of some studies in the relevant literature (Minton \& Minton, 2004; Pace, 2001). The lack of mediating role of external functional emotion regulation strategies gives rise to the thought that bullying, verbal assault, physical assault, hitting or breaking things, and trying to make others feel bad may direct effects rather than a role of mediation.

\section{Strengths and Limitations}

An important factor indicating that the current study is statistically powerful is that the mediation of emotion regulation strategies in the relationship between positive and negative affect and depressive symptoms in adolescents was tested and the mediating powers of each mediating variable were compared and examined together through parallel multiple mediation analysis. Also, the topic of depressive symptoms in adolescents extensively studied within the relevant literature presents factors leading to clearer understanding of the findings of current research. For instance, depressive symptoms examined within the network of connections and mutual interaction process in adolescent-parent relational dimension may lead to better understanding of concepts. Another limitation in the current study is

\section{References}

Anderson, C. A., Miller, R. S., Riger, A. L., Dill, J. C., \& Sedikides, C. (1994). Behavioral and characterological styles as predictors of depression and loneliness: review, refinement, and test. Journal of Personality and Social Psychology, 66, 549-558. doi: 10.1037/0022-3514.66.3.549.

Arditte, K., \& Joorman, J. (2011). Emotion regulation in depression: reflection predicts recovery from a major depressive episode. Cognition and Emotion, 31, 2276-2388. doi: 10.1007/s10608-011-9389-4.

Barlow, D. H., Allen, L. B., \& Choate, M. L. (2004). Toward a unified treatment for emotional disorders. Behavior Therapy, 35(2), 205-230. doi: 0.1016/j.beth.2015.07.002.

Baytemir, K., \& Yildiz, M. A. (2017). Multiple mediation of loneliness and negative affects in the relationship between adolescents' social anxiety and depressive symptoms. Anales de Psicología, 33(3), 612-620. http://dx.doi.org/10.6018/analesps.33.3.269211

Bhasin, S. K., Sharma, R., \& Saini, N. K. (2010). Depression, anxiety and stress among adolescent students belonging to affluent families: A school-based study. Indian Journal of Pediatrics, 77(2), 161-165.

Campbell-Sills, L., Barlow, D. H., Brown, T.A., \& Hofmann, S. G. (2006). Effects of suppression and acceptance on emotional responses of individuals with anxiety and mood disorders. Behaviour Research and Therapy, 44, 1251-1263. doi: 10.1016/j.brat.2005.10.001.

Cohen, L., Manion, L., \& Morrison, K. (2007). Research methods in education (Sixth edition.). London: Routledge.

Collins, A., \& Miller, L. C. (1994). Self-disclosure and liking: A metaanalytic review. Psychological Bulletin, 116, 457-475. doi: http://dx.doi.org/10.1037/0033-2909.116.3.457. about adolescents' emotional ups and downs in adolescence. The responses provided by adolescents in measures may have been affected by those emotional fluctuations. Study results must be considered accordingly.

\section{Implications for Research, Policy and Practice}

Considering the depressive symptoms associated with psychological health, defining positive and negative affect through emotion regulation strategies may provide a functional perspective for researchers and practitioners employed in the field of Psychological Counseling and Guidance. Also, depressive symptoms in adolescents may be examined within attachment and socialization pattern. Based on the gender differences in the occurrence frequency of depressive symptoms, the gender differences among groups may be examined through multi-group structural equation model. In addition, based on the personal dimension of depressive symptoms, adolescent-parent relationship cycle may be examined within the context of mutual interaction. Psycho-educational activities conducted for developing emotion regulation skills by school psychological counselors for adolescents with high levels of depressive symptoms may be useful. In addition, studies on adolescents, especially those related to emotional regulation, need to be achieved in a longer period of time. Thus, as the adolescents are in the developmental period they are in, the variability of emotional states may become more stable. Based on the social influence by the adolescent population, it may be beneficial for overall mental health in the community in the long run to review the educational and health policies to prevent depressive symptoms as the mostencountered mental distress in adolescents and to finance more extensive research and projects through relevant public organizations.

Compare, A., Zarbo, C., Shonin, E., Van Gordon, W., \& Marconi, C. (2014). Emotional regulation and depression: A potential mediator between heart and mind. Cardiovascular Psychiatry and Neurology, 1-11. doi: $10.1155 / 2014 / 324374$.

Duy, B., \& Yıldız, M. A. (2014). Ergenler için duygu düzenleme ölçeğinin Türkçe'ye uyarlanmasi [Adaptation of the Regulation of Emotions Questionnaire (REQ) for Adolescents]. Türk Psikolojik Damısma ve Rehberlik Dergisi, 5(41), 23-35.

Duy, B., \& Yildiz, M. A. (2017). The predictive role of emotion regulation strategies on depressive and psychosomatic symptoms in adolescents. Current Psychology, doi: 10.1007/s12144-017-9616-6.

Evans, D. W. (1994). Self-complexity and its relation to development, symptomatology and self-perception during adolescence. Child Psychiatry Human Development, 24, 173-182. doi: 10.1007/BF02353194.

Garnefski, N., Kommer, T. V. D., Kraaij, V., Teerds, J., Legers-tee, J., \& Onstein, E. (2002). The relationship between cognitive emotion regulation strategies and emotional problems: comparison between a clinical and a non-clinical sample. European Journal of Personality, 16, 403-420. doi: $10.1002 /$ per.458.

Garnefski, N., Kraaij, V., \& Van Etten, M. (2005). Specificity of relations between adolescents' cognitive emotion regulation strategies and internalizing and externalizing psychopathology. Journal of Adolescence, 28, 619-631. doi: 10.1016/j.adolescence.2004.12.009.

Gross, J. J. (1998). The emerging field of emotion regulation: An integrative review. Review of General Psychology, 2(3), 271-299. doi: 10.1037/10892680.2.3.271 
Gross, J. J. (1999). Emotion regulation: Past, present, future. Cognition and Emotion, 13(5), 551-573. doi: 10.1080/026999399379186.

Gross, J. J. (2002). Emotion regulation: Affective, cognitive, and social consequences. Psychophysiology, 39, 281-291. doi: 10.1017.S0048577201393198.

Gross, J. J. (2008). Emotion regulation. In M. Lewis, J. M. Haviland-Jones \& L. F. Barrett (Eds.), Handbook of emotions. (3rd ed.), (pp. 497-512). New York: Guilford Press.

Gross, J. J., \& John, O. P. (2003). Individual differences in two emotion regulation processes: Implications for affect, relationships, and wellbeing. Journal of Personality and Social Psychology, 85, 348-362. doi: 10.1037/0022-3514.85.2.348. 348.

Gross, J. J., Richards, J. M., \& John, O. P. (2006). Emotion regulation in everyday life. In. D. K. Snyder, J. A. Simpson \& J. H. Hughes (Eds.), Emotion regulation in couples and families: Pathways to dysfunction and health. (pp. 13-35). Washington DC: American Psychological Association.

Hashmi, S. (2013). Adolescence: an age of storm and stress. Review of Arts and Humanities, 2(1), 19-33.

Hayes, A. F. (2013). Introduction to mediation, moderation, and conditional process analysis: A regression-based approach. New York: Guilford Press.

Hayes, A. F. (2016). The PROCESS macro for SPSS and SAS. Retrieved December 2016, http:/ / www.processmacro.org/ download.html

Heppner, P. P., Wampold, B. E., \& Kivlighan, D. M., Jr. (2013). Psikolojik danıșmada arastırma yöntemleri [Research Methods in Counseling] (D. M. Siyez, Çev.) (1. bs.). Ankara: Mentis Yayıncilik.

John, O. P., \& Gross, J. J. (2004). Healthy and unhealthy emotion regulation: Personality processes, individual differences, and life span development. Journal of Personality, 72(6), 1301-1333. doi: 10.1111/j.14676494.2004.00298.x.

Joormann, J., and Gotlib, I. H. (2010). Emotion Regulation in Depression: Relation to Cognitive Inhibition. Cognition and Emotion, 24, 281-298. Doi: 10.1080/02699930903407948

Katz, I. M., \& Campbell, J. D. (1994). Ambivalence over emotional expression and wellbeing: Nomethetic and ideographic tests of the stress buffering hypothesis. Journal of Personality and Social Psychology, 67, 513524. doi: 10.1037/0022-3514.67.3.513.

Kenndy-Moore, E., \& Watson, J. C. (2001). How and when does emotional expression help? Review of General Psychology, 5,187-212. doi: 10.1037//1089-2680.5.3.187.

Koole, S. L. (2009). The psychology of emotion regulation: An integrative review. Cognition and Emotion, 23(1), 4-41. doi: 10.1080/02699930802619031.

Kovacs, M. (1981). Rating Scale to assess depression in school aged children. Acta Paedopsychiatrica, 46, 305-315. doi: 10.11919/j.issn.10020829.215115.

Kubany, E. S., Haynes, S. N., Abueg, F. R., Manke, F. P., Brennan, J. M., \& Stahura, C. (1996). Development and validation of the trauma-related guilt inventory (TRGI). Psychological Assessment, 80, 428-444. doi: http://dx.doi.org/10.1037/1040-3590.8.4.428.

Laurent, J., Catanzaro, S.J., Joiner, T.E., Rudolph, K.D. \& Potter, K.I., Lambert, S., Osborne, L., Gathright, T. (1999). A measure of Positive and Negative affect for children: Scale development and preliminary validation. Psychological Assessment, 11, 326-338.

Lepore, S. J., Ragan, J., \& Jones, S. (2000). Talking facilitates cognitiveemotional processes of adaptation to an acute stressor. Journal of Personality and Social Psychology, 78, 499-509. doi: 10.1037//00223514.78.3.499.

Leue, A., \& Lange, S. (2011). Reliability generalization: An examination of the positive affect and negative affect schedule. Assessment, 18, 487-501. doi: $10.1177 / 1073191110374917$.

Martin, R. C., \& Dahlen, E. R. (2005). Cognitive emotion regulation in the prediction of depression, anxiety, stress, and anger. Personality and Individual Differences, 39, 1249-1260. doi: 10.1016/j.paid.2005.06.004.

McLaughlin, K. A., Hatzenbuehler, M. L., Mennin, D. S., \& NolenHoeksama, S. (2012). Emotion dysregulation and adolescent psycho- pathology: A prospective study. Behaviour Research and Therapy, 49(9), 1 11. doi: 10.1016/j.brat.2011.06.003.

Mennin, D. S. (2006). Emotion regulation therapy: an integrative approach to treatment-resistant anxiety disorders. Journal of Contemporary Psychotherapy, 36(2), 95-105. doi: 10.1007/s10879-006-9012-2.

Minton, S. J., \& Minton, P. (July, 2004). An application of certain phenomenological / existential perspectives in understanding the bully-victim cycle. Existential Analysis, 15(2), 230-242.

Morrison, J. (2016). DSM-5 i Kolaylaștıran klinisyenler için tam rehberi (Cev. Ed. M. Sahin ve Hanife Uğur Kural), (1. Basım). [Made easy the clinician's guide to diagnosis] Ankara: Nobel Yayıncllık.

National Mental Health Institute (2016). Depression. Retrieved February 2017, https://www.nimh.nih.gov/health/topics/depression/index.shtml

Nolen-Hoeksema, S. (2000). Growth and resilience among bereaved people. In J. Gillham (Ed.), Dimensions of optimism and hope. (pp. 107-128). Philadelphia: Templeton Foundation Press.

Nolen-Hoeksema, S., Stice, E., Wade, E., \& Bohon, C. (2007). Reciprocal relations between rumination and bulimic, substance abuse, and depressive symptoms in adolescent females. Journal of Abnormal Psychology, 116, 198-207. doi: 10.1037/0021-843X.116.1.198.

Öy, B. (1991). Çocuklar için depresyon ölçeği: Geçerlik ve güvenirlik çalışması. [Depression scale for children: reliability and validity studies]. Türk Psikiyatri Dergisi, 2,132-137.

Pace, B. (April, 2001). Bullying. JAMA, 285(16), 2158-2159. doi: 10.1001/jama.285.16.2094.

Phillips, K. F. V., \& Power, M. J. (2007). A new self-report measure of emotion regulation in adolescents: The regulation of emotions questionnaire. Clinical Psychology and Psychotherapy, 14, 145-156. doi: $10.1002 /$ cpp. 523.

Siener, S., \& Kerns, K. A. (2012). Emotion regulation and depressive symptoms in preadolescence. Child Psycbiatry Human Development, 43(4), 414 430. doi: 10.1007/s10578-011-0274-x.

Singer, A.R., \& Dodson, K. S. (2007). An experimental investigation of the cognitive vulnerability to depression. Behaviour Research and Therapy, 45(3), 563-575. doi: 10.1016/j.brat.2006.05.007.

Smith, J. M., \& Alloy L. B. (2009). A roadmap to rumination: a review of the definition, assessment, and conceptualization of this multifaceted construct. Clinical Psychology Review, 29(2), 116-128. doi: 10.1016/j.cpr.2008.10.003.

Tabachnick, B. G., and Fidell, L. S. (2013). Using Multivariate Statistics, 6th Edition. Boston, MA: Pearson.

Turkey Statistical Institution [Türkiye İstatistik Kurumu] (2013). Istatistiklerle Gençlik Haber Bülteni. Retrieved February 2017, from http:/ / www.tuik.gov.tr/PreHaberBultenleri.do?id=16055.

Verzeletti, C., Zammuner, V. L., Galli, C., \& Agnoli, S. (2016). Emotion regulation strategies and psychosocial well-being in adolescence. Cogent Psychology, 3(1199294), 1-15. doi: http://dx.doi.org/10.1080/23311908.2016.

World Health Organization (2014). Depression. Retrieved February 2017, from http://www.who.int/mediacentre/factsheets/fs369/en/.

World Health Organization (2015). Depression. Retrieved January 2017, from http://www.euro.who.int/en/countries/turkey.

Yildı, M. A. (2014). Ergenlerde anne-babaya bağlanma ile öznel iyi olus arasindaki ilişkide duygu düzenleme ve baş etme yöntemlerinin çoklu araculk. rolü [The multiple mediating role of emotion regulation and coping strategies on the relationship between parental attachment and subjective wellbeing in adolescents]. Doctoral dissertation, Mersin University, Mersin, Turkey.

Yildız, M. A. (2016). Multiple mediation of emotion regulation strategies in the relationship between loneliness and positivity in adolescents. Education and Science, 186, 217-231. doi: 10.15390/EB.2016.6193

Zech, E. (1998). Is it helpful to verbalize ones emotions? Gedrag and Gezondheid, 27, 42-47. doi: 10.1007/bf01173204.

(Article received: 28-05-2017; revised: 15-09-2017; accepted: 18-10-2017) 